\title{
Supporting Information for Passivation of Germanium by Graphene for Stable Graphene/Germanium Heterostructure Devices
}

Robert M. Jacobberger ${ }^{\S}$, Matthew J. Dodd ${ }^{\S}$, Marziyeh Zamiri ${ }^{\dagger}$, Austin J. Way, Michael S. Arnold, and Max G. Lagally*

Department of Materials Science and Engineering, University of Wisconsin-Madison, Madison, Wisconsin 53706, United States

$\S$ These authors contributed equally to the work.

${ }^{\dagger}$ Current Address: Department of Electrical and Computer Engineering, University of Ottawa, Ottawa, Ontario K1N 6N5, Canada.

*E-mail: lagally@engr.wisc.edu.

Determination of Nucleation Density from Partial Growths. The $\rho_{\text {grain }}$ within a continuous film is estimated from SEM images of individual graphene islands grown with submonolayer coverage by reducing the growth time (Figure 4). The lower bound for $\rho_{\text {grain }}$ is determined by dividing the number of graphene islands by the area of the substrate, which assumes that only those islands that already exist will coalesce to form a continuous film (i.e., no additional nucleation occurs). The upper bound for $\rho_{\text {grain }}$ is determined by dividing the number of graphene islands by the area of the substrate and then dividing by the graphene coverage, which assumes that the continuous film will consist of grains with the same size as measured in the submonolayer growth. During growth, the graphene islands that exist will grow larger and additional nuclei will also form and, thus, the grain density within a continuous film will likely fall between the calculated lower and upper bounds in Figure 4.

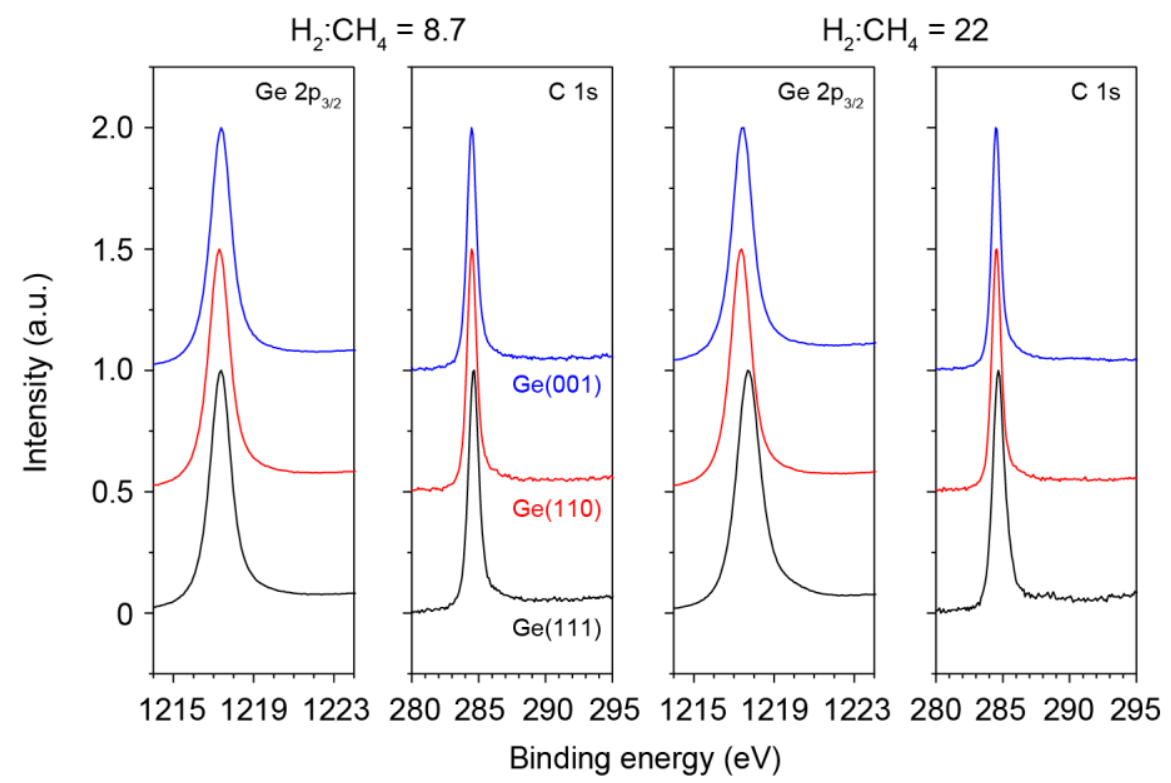

Figure S1 XPS Ge 2p $\mathrm{p}_{3 / 2}$ and C 1s Peaks Directly after Growth. Plot of intensity of the XPS Ge $2 \mathrm{p}_{3 / 2}$ (first and third columns) and $\mathrm{C} 1 \mathrm{~s}$ peak (second and fourth columns) against binding energy for graphene on $\mathrm{Ge}(111)$ (bottom, black), $\mathrm{Ge}(110)$ (red), and $\mathrm{Ge}(001)$ (blue, top) directly after growth. The samples are grown with $\mathrm{H}_{2}: \mathrm{CH}_{4}$ of 8.7 (first and second columns) and 22 (third and fourth columns) at $910{ }^{\circ} \mathrm{C}$ for $6 \mathrm{~h}$. 


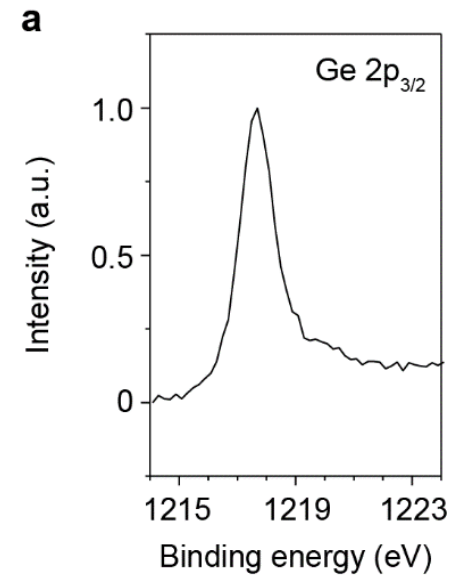

b

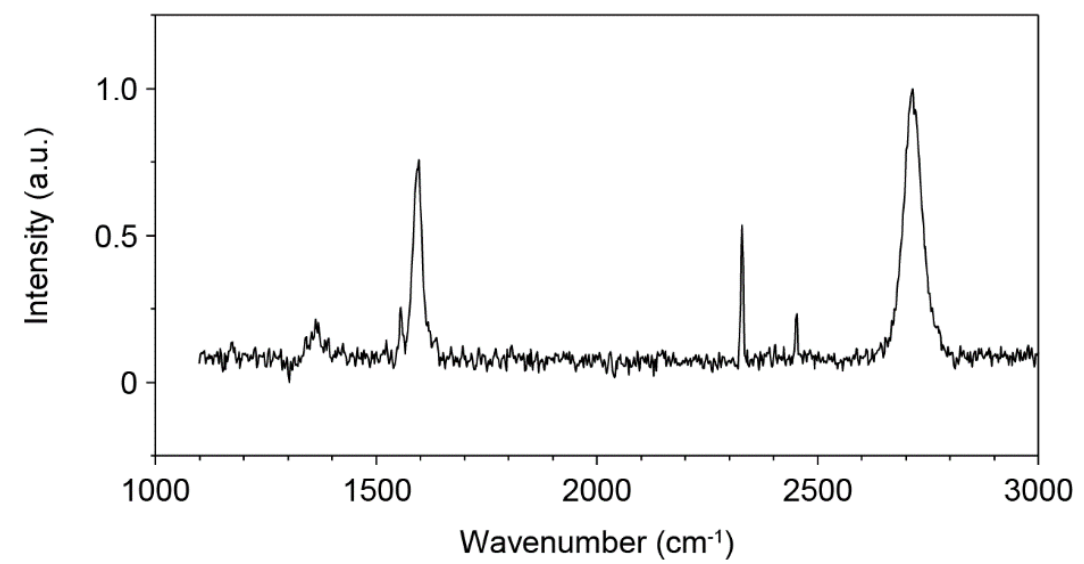

Figure S2 Passivation of $\mathbf{G e}(001)$ with Increased $\mathbf{H}_{2}: \mathbf{C H}_{4}$. Graphene is grown on $\mathrm{Ge}(001)$ at $910{ }^{\circ} \mathrm{C}$ for $15 \mathrm{~h}$ using $\mathrm{H}_{2}: \mathrm{CH}_{4}$ of 28 . (a) Plot of intensity of the XPS Ge $2 \mathrm{p}_{3 / 2}$ peak against binding energy after exposing the sample to air at room temperature for 1 month. (b) Plot of Raman intensity versus wavenumber for the sample. $\mathrm{Ge}(001)$ remains passivated (i.e., the $\mathrm{GeO}_{2}$ XPS peak is negligible) after 1 month of exposure to air. Passivation of $\mathrm{Ge}(001)$ is improved compared to Figure 1 by conducting growth with higher $\mathrm{H}_{2}: \mathrm{CH}_{4}$ as well as increasing the growth time to ensure full coverage of the Ge surface by graphene.

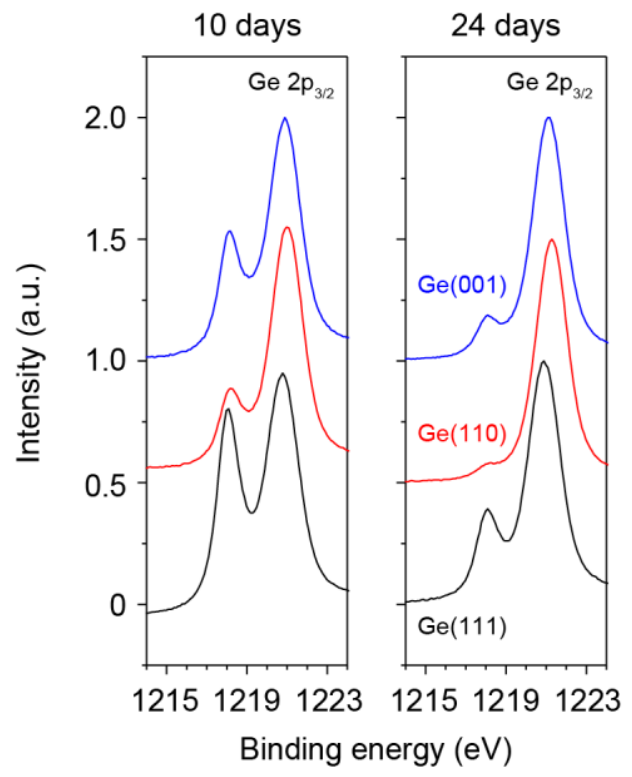

Figure S3 Oxidation of Ge Surfaces That Are Not Covered with Graphene. Plot of intensity of the XPS Ge 2 $p_{3 / 2}$ peak against binding energy for bare Ge(111) (bottom, black), Ge(110) (red), and Ge(001) (blue, top) surfaces after being stored in ambient air at room temperature for 10 days (left column) and 24 days (right column). Before exposure to air, the samples are annealed at $910{ }^{\circ} \mathrm{C}$ in a flow of $200 \mathrm{sccm}$ of Ar and $100 \mathrm{sccm}$ of $\mathrm{H}_{2}$ for $6.5 \mathrm{~h}$. These samples are subjected to roughly the same growth conditions as those in the main text, except that no $\mathrm{CH}_{4}$ is flowed so that graphene is not synthesized. 

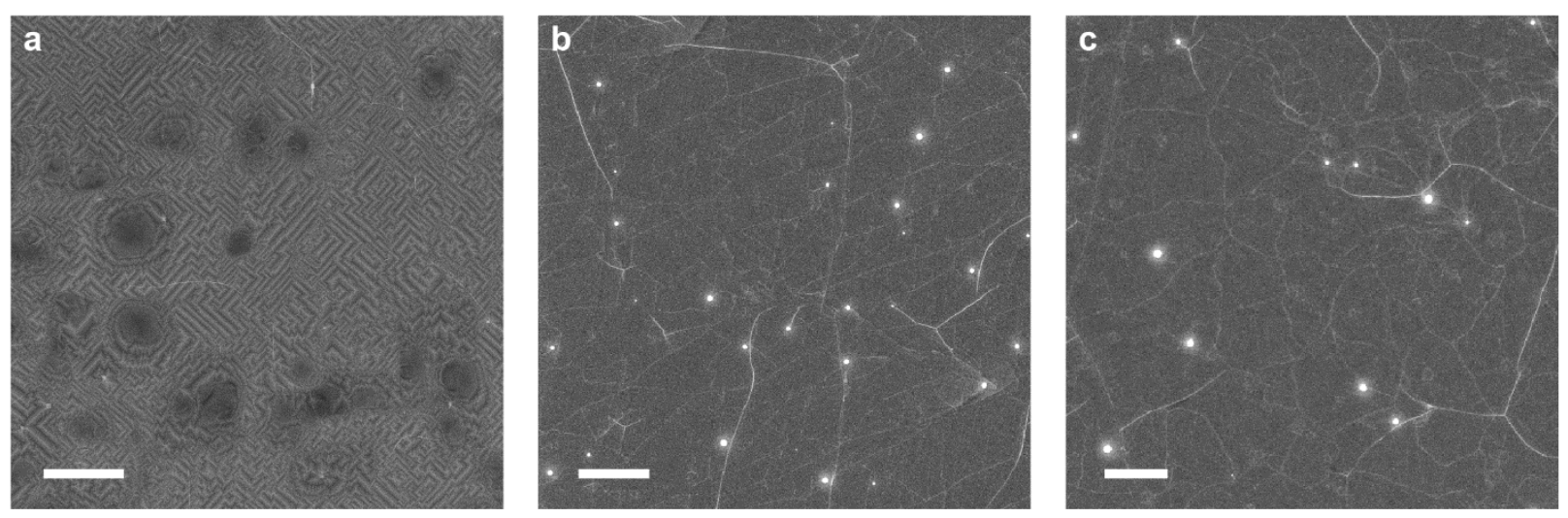

Figure S4 SEM Images of Continuous Graphene Films. (a-c) SEM images of continuous graphene films on $\mathrm{Ge}(001)$ (a), $\mathrm{Ge}(110)$ (b), and $\mathrm{Ge}(111)$ (c). The films appear to be completely continuous for all $\mathrm{Ge}$ surface orientations when viewed with SEM. Therefore, any defects that exist in these films are smaller than the resolution of SEM (i.e., $<10 \mathrm{~nm}$ in size). Scale bars are $1 \mu \mathrm{m}$.
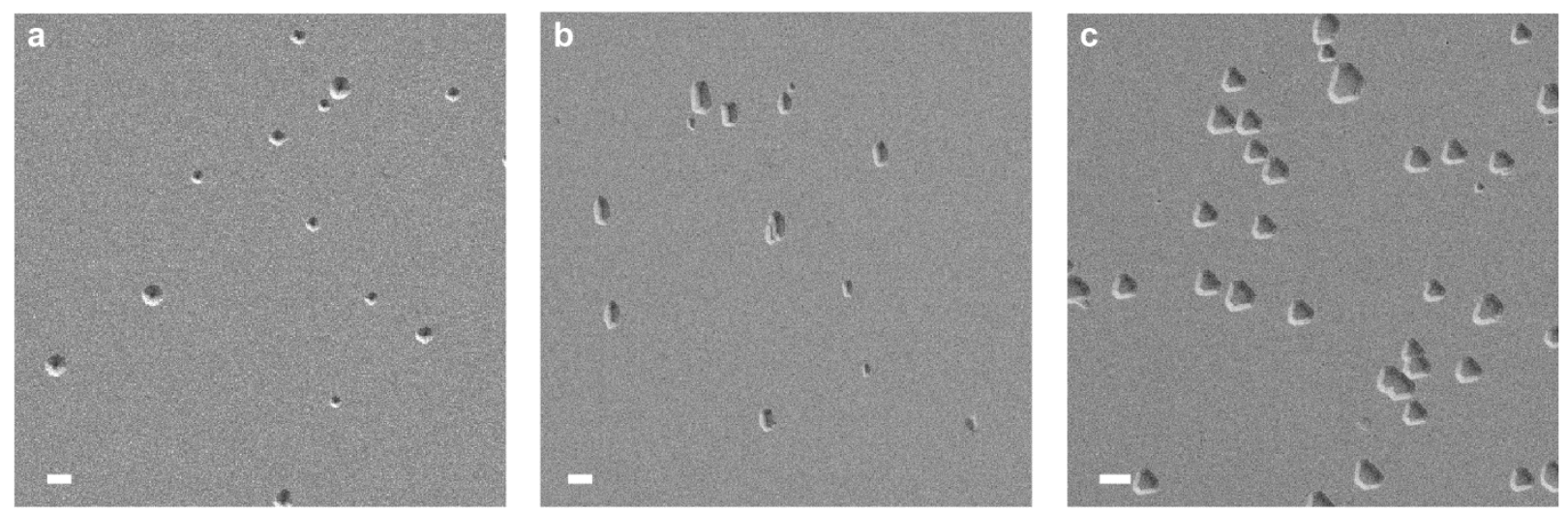

Figure S5 Ge Etch Pits Below Graphene. (a-c) SEM images of continuous graphene films grown on $\mathrm{Ge}(001)$ (a), $\mathrm{Ge}(110)$ (b), and $\mathrm{Ge}(111)$ (c) after the samples are exposed to $\mathrm{FeCl}_{3}$ to create etch pits selectively in the Ge surface below pinholes in graphene. Scale bars are $2 \mu \mathrm{m}$. 

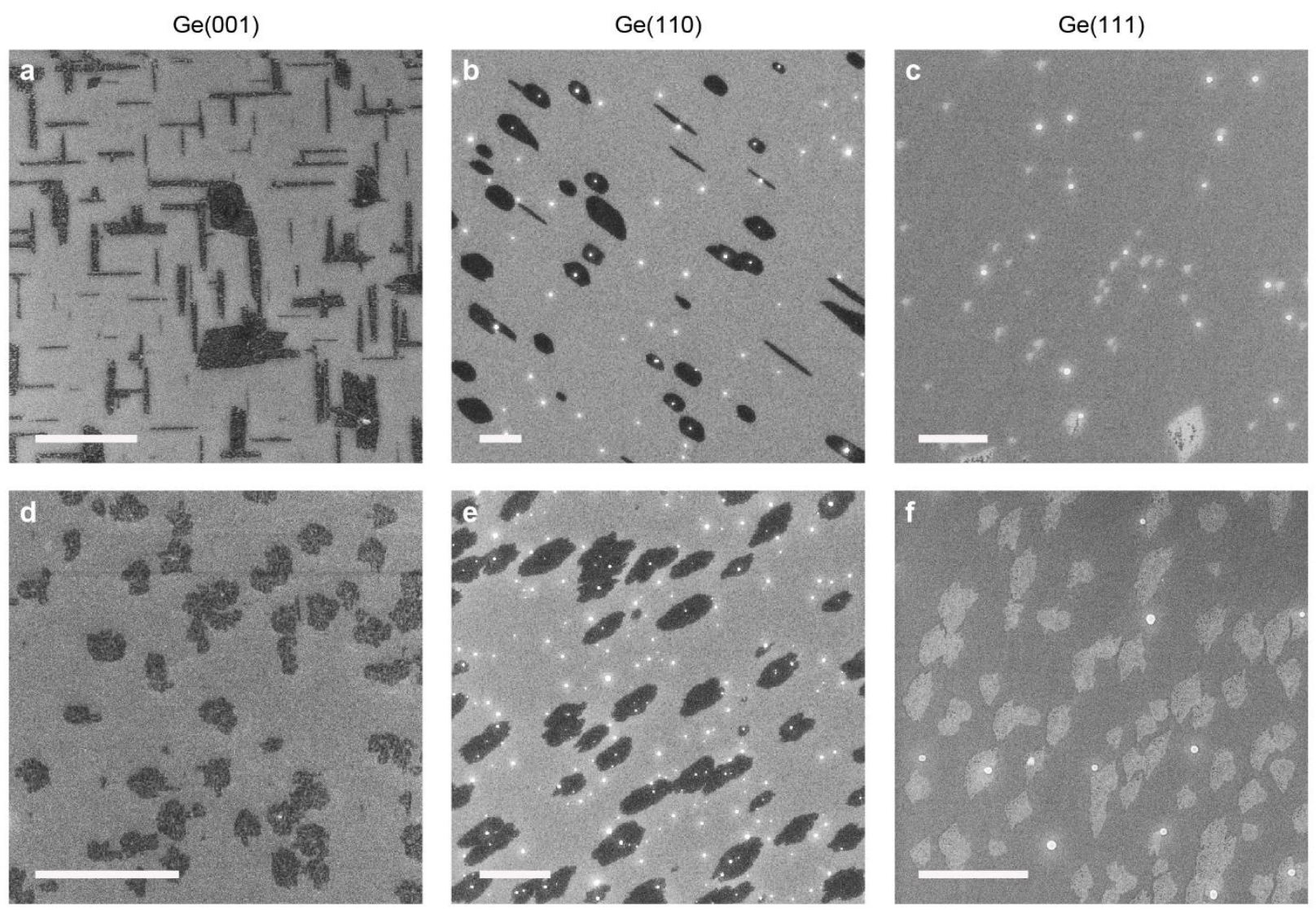

Figure S6 SEM Images of Isolated Graphene Islands. (a-f) SEM images of isolated graphene islands grown at submonolayer coverage on $\mathrm{Ge}(001)(\mathrm{a}, \mathrm{d}), \mathrm{Ge}(110)(\mathrm{b}, \mathrm{e})$, and $\mathrm{Ge}(111)(\mathrm{c}, \mathrm{f})$ using an $\mathrm{H}_{2}: \mathrm{CH}_{4}$ ratio of 22 (a-c) and 13 (d-f) at $910^{\circ} \mathrm{C}$ for 90 (a-c), 6 (d), and 10 (e,f) min. Scale bars are $1 \mu \mathrm{m}$. Contrast reversal is attributed to amorphous carbon deposition upon sample exposure to the electron beam and oxidation of the Ge surface, which depend on the amount of time the sample is exposed to air before imaging as well as the magnification and number of scans used during imaging. ${ }^{1}$ From such SEM images, the growth rate is calculated by dividing the average island size by the growth time. The extracted growth rates are 0.018 (a), 0.133 (b), 0.015 (c), 0.261 (d), 0.643 (e), and 0.179 (f) $\mu \mathrm{m}^{2} \mathrm{~h}^{-1}$. For each $\mathrm{H}_{2}: \mathrm{CH}_{4}$ ratio, the growth rate per island is higher on $\mathrm{Ge}(110)$ than on $\mathrm{Ge}(001)$ and $\mathrm{Ge}(111)$. For each Ge surface orientation, the growth rate increases with decreasing $\mathrm{H}_{2}: \mathrm{CH}_{4}$ ratio, consistent with previous results of graphene growth on $\mathrm{Ge}$ surfaces. ${ }^{2}$ Furthermore, for each Ge surface orientation, the graphene islands are more uniform in size at lower $\mathrm{H}_{2}: \mathrm{CH}_{4}$ ratio. On $\mathrm{Ge}(111)$, the graphene islands are roughly hexagonal. On $\mathrm{Ge}(110)$, the graphene islands are roughly elliptical, and some islands are more elongated and anisotropic at higher $\mathrm{H}_{2}: \mathrm{CH}_{4}$ ratio. On $\mathrm{Ge}(001)$, the graphene islands are roughly circular at lower $\mathrm{H}_{2}: \mathrm{CH}_{4}$ ratio and are predominately elongated, anisotropic rectangles (i.e., nanoribbons) at higher $\mathrm{H}_{2}: \mathrm{CH}_{4}$ ratio. 
a

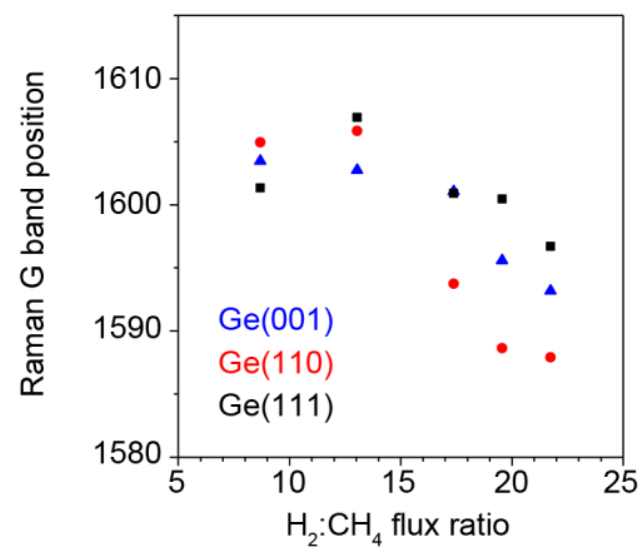

C

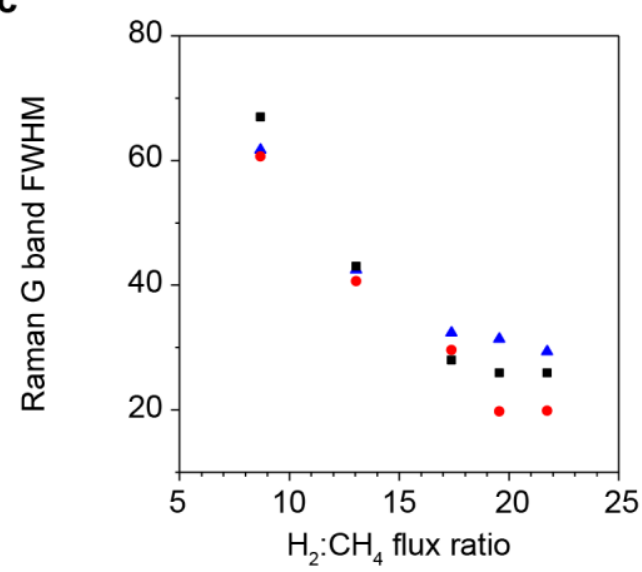

b

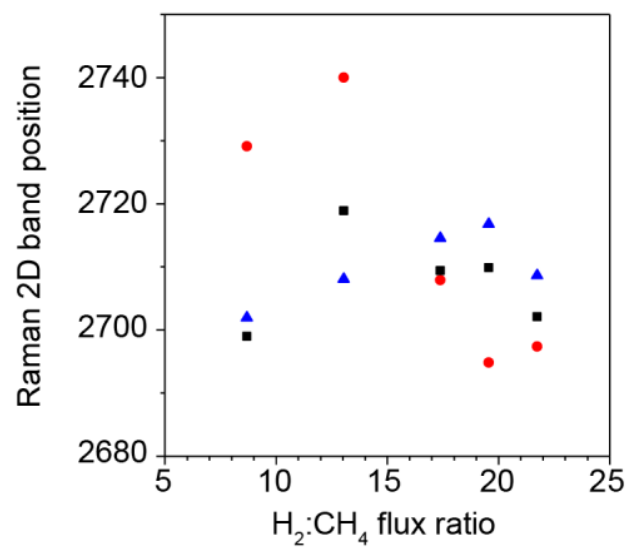

d

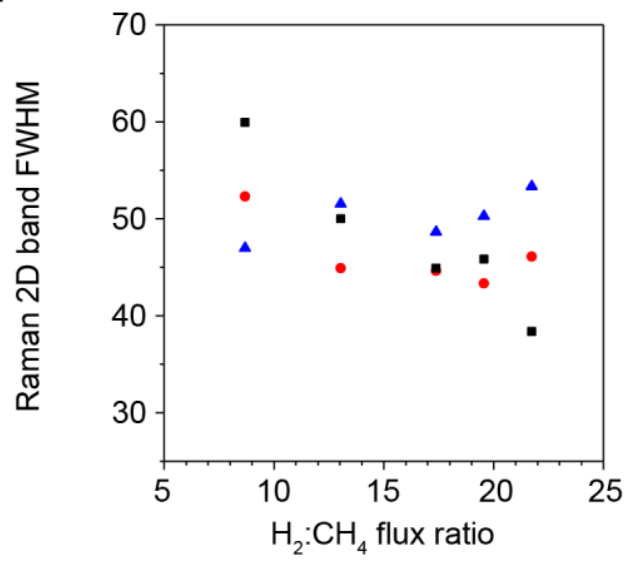

Figure S7 Characterization of the Raman Peak Positions and Widths. (a-d) Plots of the Raman G band position (a), 2D band position (b), G band full-width at half-maximum (FWHM) (c), and 2D band FWHM (d) versus $\mathrm{H}_{2}: \mathrm{CH}_{4}$ flux ratio for graphene grown on $\mathrm{Ge}(001)$ (blue triangles), $\mathrm{Ge}(110)$ (red circles), and $\mathrm{Ge}(111)$ (black squares). In general, the $\mathrm{G}$ peak position shifts to lower wavenumbers and becomes narrower with increasing $\mathrm{H}_{2}: \mathrm{CH}_{4}$ ratio on all Ge surface orientations, which indicates that graphene is becoming more crystalline, as also indicated by the decrease in Raman D:G ratio shown in Figure 3a-c. The position of the $\mathrm{D}$ band (not plotted above) is half the wavenumber value of the position of the $2 \mathrm{D}$ band.

Effect of $\mathrm{H}_{2}: \mathrm{CH}_{4}$ Ratio and Ge Surface Orientation on Multilayer Graphene Coverage. The effect of $\mathrm{H}_{2}: \mathrm{CH}_{4}$ ratio on the coverage of graphene multilayers is studied. To quantify multilayer coverage, graphene films are transferred from $\mathrm{Ge}$ onto $\mathrm{SiO}_{2}$, which enhances the contrast between monolayer and multilayer regions of graphene, using a wet transfer process. Briefly, PMMA is spin-coated onto graphene. The sample is floated on a solution of HF: $\mathrm{H}_{2} \mathrm{O}_{2}: \mathrm{H}_{2} \mathrm{O}$ to etch the Ge substrate. The resulting graphene/PMMA membrane is then washed multiple times in deionized $\mathrm{H}_{2} \mathrm{O}$ and is lifted onto an $\mathrm{SiO}_{2}$ substrate. The PMMA is removed by rinsing with acetone, followed by thermal annealing in a vacuum of $\sim 10^{-5}$ torr at $400{ }^{\circ} \mathrm{C}$ for $1 \mathrm{~h}$. Figure $\mathrm{S} 8$ shows that the coverage of multilayers generally increases with increasing $\mathrm{H}_{2}: \mathrm{CH}_{4}$ ratio. However, the increase is much smaller on $\mathrm{Ge}(110)$ and $\mathrm{Ge}(111)$ than on $\mathrm{Ge}(001)$. 
a

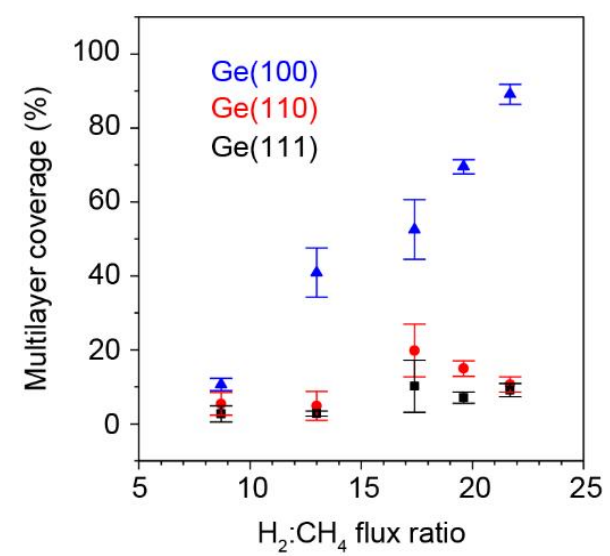

b

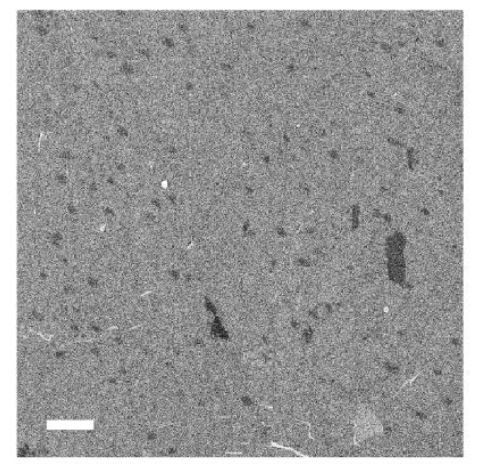

C

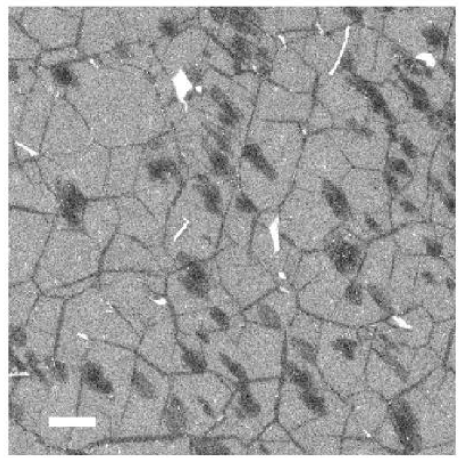

Figure S8 Effect of $\mathrm{H}_{2}: \mathrm{CH}_{4}$ Ratio and Ge Surface Orientation on Multilayer Graphene Coverage. (a) Plot of multilayer coverage against $\mathrm{H}_{2}: \mathrm{CH}_{4}$ ratio for graphene grown on $\mathrm{Ge}(001)$ (blue triangles), $\mathrm{Ge}(110)$ (red circles), and $\mathrm{Ge}(111)$ (black squares) at $910{ }^{\circ} \mathrm{C}$ for $6 \mathrm{~h}$. (b,c) SEM images of graphene grown on $\mathrm{Ge}(110)$ with an $\mathrm{H}_{2}: \mathrm{CH}_{4}$ ratio of 8.7 (b) and 22 (c) after transfer onto $\mathrm{SiO}_{2}$ to more easily visualize the multilayer domains (regions of darker contrast). Scale bars are $2 \mu \mathrm{m}$.
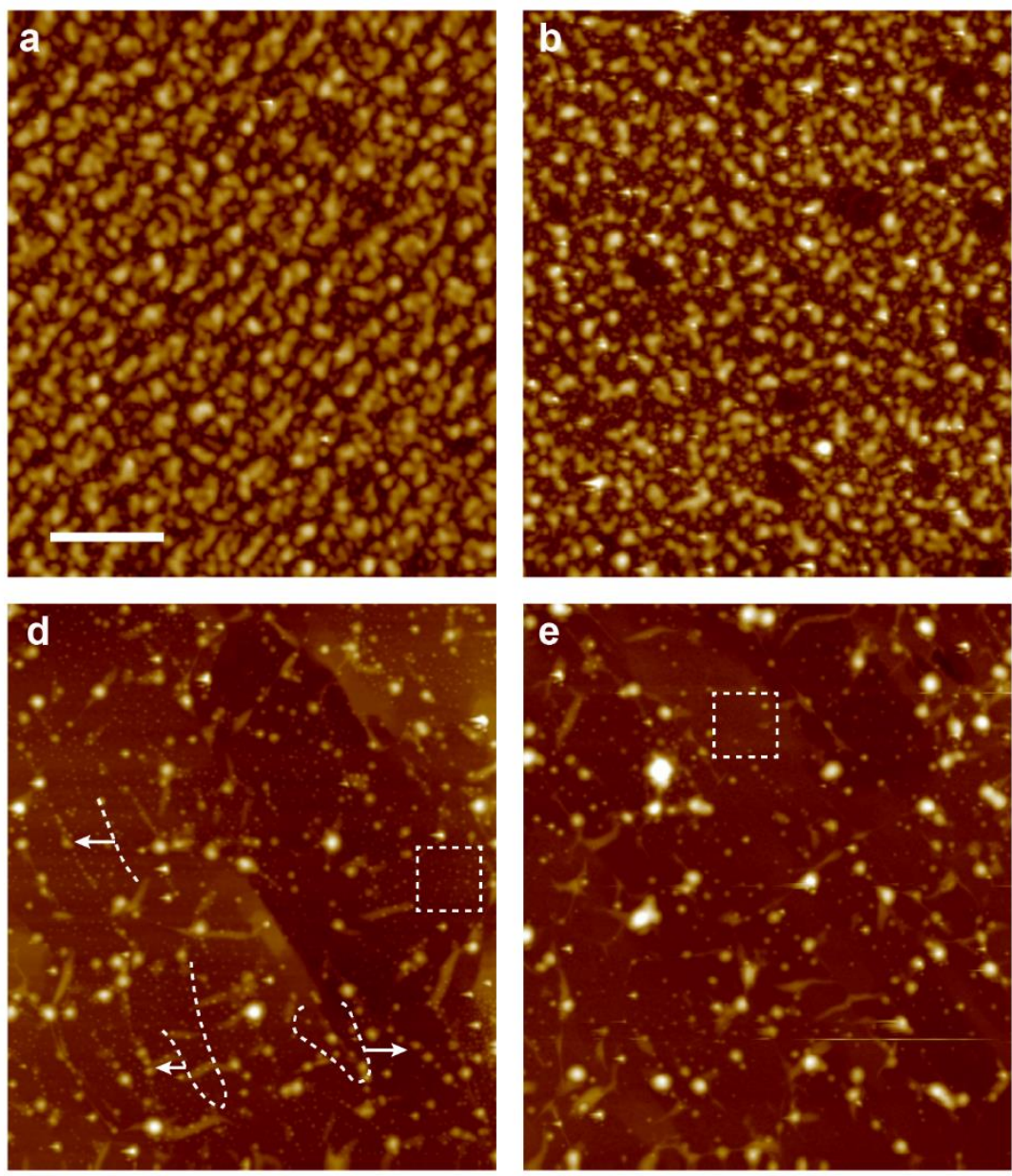
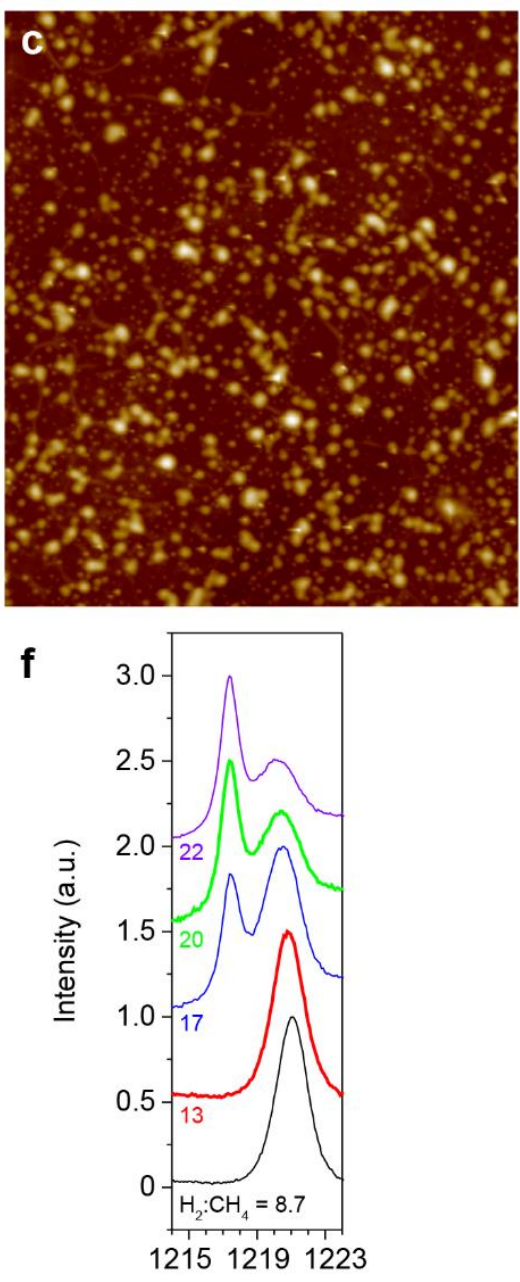

Binding energy $(\mathrm{eV})$ 
Figure S9 AFM Topographic Images of Graphene/Ge(110) after Exposure to Air for 19.5 Months. (a-e) AFM images of graphene grown with an $\mathrm{H}_{2}: \mathrm{CH}_{4}$ ratio of 8.7 (a), 13 (b), 17 (c), 20 (d), and 22 (e) on $\mathrm{Ge}(110)$ after exposing the samples to air for 19.5 months. Scale bar is $2 \mu \mathrm{m}$ and height scale is $100 \mathrm{~nm}$. (f) Plot of intensity of the XPS Ge $2 \mathrm{p}_{3 / 2}$ peak against binding energy for graphene grown on $\mathrm{Ge}(110)$ with an $\mathrm{H}_{2}: \mathrm{CH}_{4}$ ratio of 8.7 (black, bottom), 13 (red), 17 (blue), and 20 (green), and 22 (purple, top) at $910{ }^{\circ} \mathrm{C}$ for $6 \mathrm{~h}$ after being exposed to air at room temperature for 19.5 months. XPS data in (f) show that the oxidation of $\mathrm{Ge}$ increases with decreasing $\mathrm{H}_{2}: \mathrm{CH}_{4}$, as also observed in Figure 1 and Figure 5. Particles with varying density are observed on each sample in the AFM images. It is likely that the particles are $\mathrm{GeO}_{2}$, as their density increases with Ge oxidation; however, the composition of the particles cannot be determined using AFM. Some particles are distributed uniformly over the surface with spacing that is smaller than the graphene grain size (highlighted in (d) and (e) using boxes), which may indicate Ge oxidation at point defects, while other particles are positioned along linear features (highlighted in (d) with dashed lines), which may indicate Ge oxidation at grain boundaries. Additional characterization of the exact nature of the graphene sites at which Ge preferentially oxidizes will be the focus of future work.

a

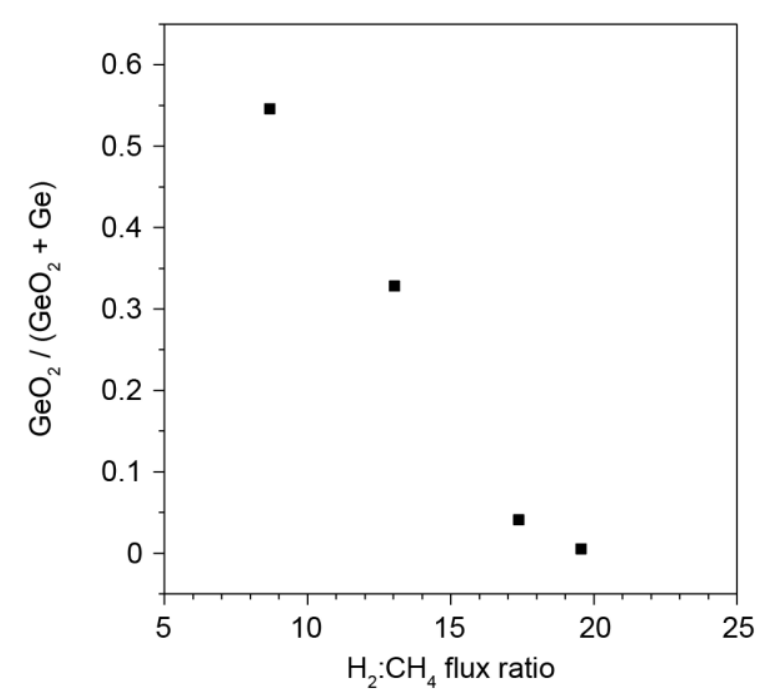

b

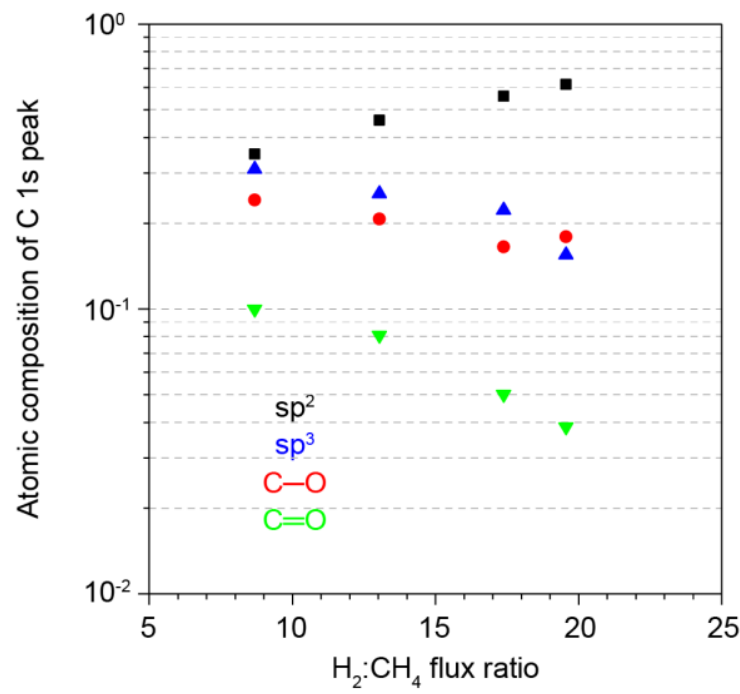

Figure S10 Analysis of the XPS Ge 2p $\mathrm{p}_{3 / 2}$ and C 1s Data in Figure 5. (a) Plot of the area of the $\mathrm{GeO}_{2}$ peak normalized to the total area of the $\mathrm{Ge}$ and $\mathrm{GeO}_{2}$ peaks against $\mathrm{H}_{2}: \mathrm{CH}_{4}$ ratio. (b) Plot of the area of different components of the $\mathrm{C} 1 \mathrm{~s}$ peak normalized to the total area of the $\mathrm{C}$ 1s peak against $\mathrm{H}_{2}: \mathrm{CH}_{4}$ ratio for $\mathrm{C}$ in the form of $\mathrm{sp}^{2}$ (black squares), $\mathrm{sp}^{3}$ (blue upward triangles), $\mathrm{C}-\mathrm{O}$ (red circles), and $\mathrm{C}=\mathrm{O}$ (green downward triangles). These data are collected from graphene grown on $\mathrm{Ge}(110)$ after exposure to atmospheric air at room temperature for 6.5 months. The relative concentration of $\mathrm{GeO}_{2}$ (a) and functionalization of the graphene lattice with $\mathrm{C}-\mathrm{O}$ as well as $\mathrm{C}=\mathrm{O}$ groups (b) increase as $\mathrm{H}_{2}: \mathrm{CH}_{4}$ is reduced. 

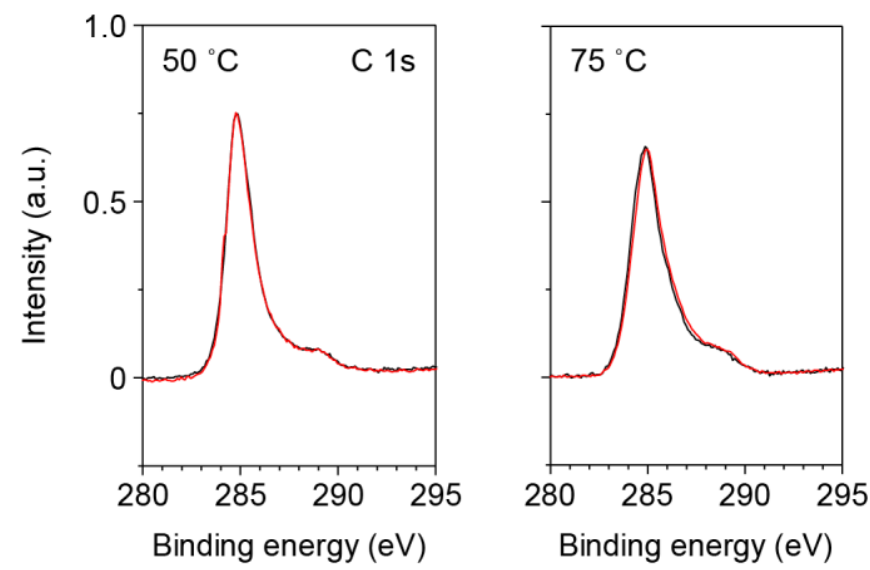

Figure S11 XPS C 1s Peak Before and After Annealing in High Vacuum. Plot of intensity of the XPS $\mathrm{C}$ 1s peak against binding energy for graphene on $\mathrm{Ge}(110)$ after being exposed to atmospheric air at room temperature for 19.5 months. Spectra are collected before (black) and after (red) annealing the sample at $50{ }^{\circ} \mathrm{C}$ for $9 \mathrm{~h}$ (left) and $75^{\circ} \mathrm{C}$ for $1 \mathrm{~h}$ (right) at $5 \times 10^{-6}$ torr to desorb weakly bound contaminants. It is necessary to anneal below $100{ }^{\circ} \mathrm{C}$ because previous work has shown that graphene oxide is reduced when annealed at $100{ }^{\circ} \mathrm{C}$ in high vacuum ${ }^{3}$ and in an inert atmosphere. ${ }^{4}$
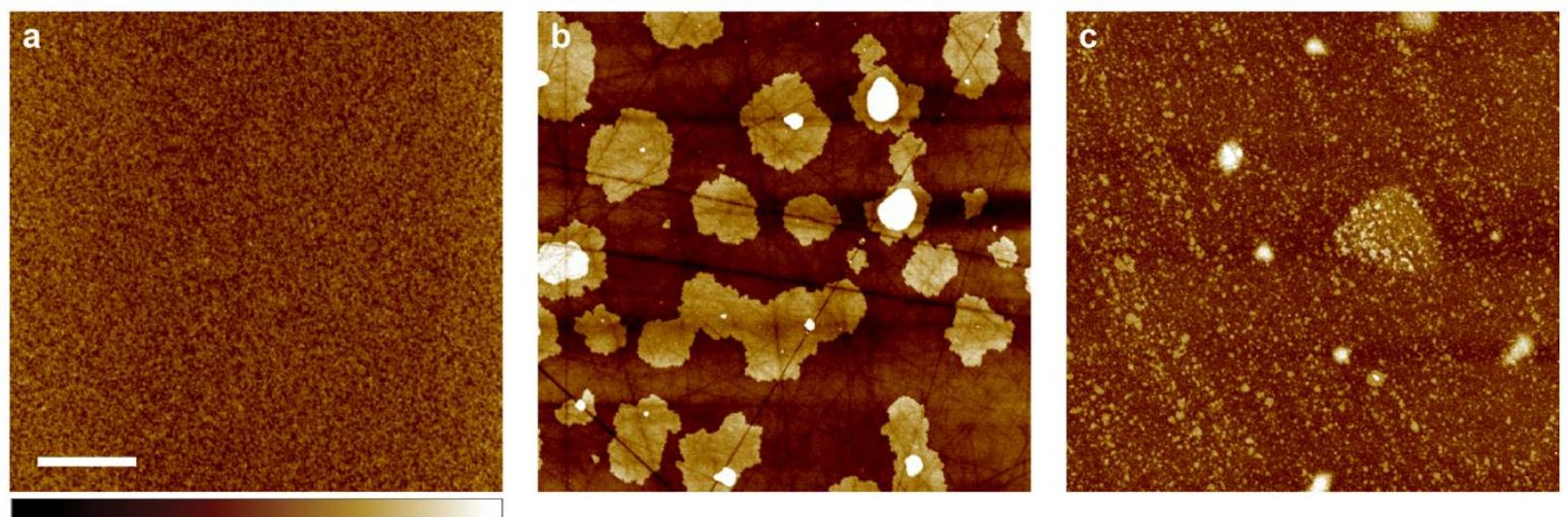

Figure S12 AFM Topographic Images of As-Purchased Ge Wafers. (a-c) AFM images of as-purchased $\mathrm{Ge}(001)$ (a), $\mathrm{Ge}(110)$ (b), and $\mathrm{Ge}(111)$ (c) wafers. The surface roughness of $\mathrm{Ge}(001), \mathrm{Ge}(110)$, and $\mathrm{Ge}(111)$ is $0.73,2.5$, and $0.98 \mathrm{~nm}$, respectively, over areas of $10 x 10 \mu \mathrm{m}^{2}$. Scale bar is $2 \mu \mathrm{m}$ and height scale is 10 $\mathrm{nm}$. During graphene growth, which is conducted near the melting point of Ge, the surface morphology of the as-purchased Ge wafers is not preserved..$^{1,2,5}$

\section{Supporting Information References}

1. Jacobberger, R. M.; Murray, E. A.; Fortin-Deschênes, M.; Göltl, F.; Behn, W. A.; Krebs, Z. J.; Levesque, P. L.; Savage, D. E.; Smoot, C.; Lagally, M. G.; Desjardins, P.; Martel, R.; Brar, V.; Moutanabbir, O.; Mavrikakis, M.; Arnold, M. S. Alignment of Semiconducting Graphene Nanoribbons on Vicinal Ge(001). Nanoscale 2019, 11, 4864-4875.

2. Jacobberger, R. M.; Kiraly, B.; Fortin-Deschenes, M.; Levesque, P. L.; McElhinny, K. M.; Brady, G. J.; Delgado, R. R.; Roy, S. S.; Mannix, A.; Lagally, M. G.; Evans, P. G.; Desjardins, P.; Martel, R.; Hersam, M. C.; Guisinger, N. P.; Arnold, M. S. Direct Oriented Growth of Armchair Graphene Nanoribbons on Germanium. Nat. Commun. 2015, 6 , 8006. 
3. Mattevi, C.; Eda, G.; Agnoli, S.; Miller, S.; Mkhoyan, K. A.; Celik, O.; Mastrogiovanni, D.; Granozzi, G.; Garfunkel, E.; Chhowalla, M. Evolution of Electrical, Chemical, and Structural Properties of Transparent and Conducting Chemically Derived Graphene Thin Films. Adv. Funct. Mater. 2009, 19, 2577-2583.

4. $\quad$ Stankovich, S.; Dikin, D. A.; Piner, R. D.; Kohlhaas, K. A.; Kleinhammes, A.; Jia, Y.; Wu, Y.; Nguyen, S. T.; Ruoff, R. S. Synthesis of Graphene-Based Nanosheets via Chemical Reduction of Exfoliated Graphite Oxide. Carbon 2007, 45, 1558-1565.

5. Kiraly, B.; Jacobberger, R. M.; Mannix, A. J.; Campbell, G. P.; Bedzyk, M. J.; Arnold, M. S.; Hersam, M. C.; Guisinger, N. P. Electronic and Mechanical Properties of GrapheneGermanium Interfaces Grown by Chemical Vapor Deposition. Nano Lett. 2015, 15, 7414-7420. 